\title{
A Longitudinal Study of the Dimensions of Disciplinary Culture to Enhance Innovation and Retention among Engineering Students
}

\author{
Mr. Homero Murzi, Virginia Tech \\ $\mathrm{PhD}$. Candidate Engineering Education at Virginia Tech.
}

\section{Prof. Thomas Martin, Virginia Tech}

Tom Martin is a Professor in the Bradley Department of Electrical and Computer Engineering at Virginia Tech, with courtesy appointments in Computer Science and the School of Architecture + Design. He is the co-director of the Virginia Tech E-textiles Lab and a Senior Fellow at the Institute for Creativity, Arts, and Technology. He received his Ph.D. in Electrical and Computer Engineering from Carnegie Mellon University and his B.S. in Electrical Engineering from the University of Cincinnati. His research and teaching interests include wearable computing, electronic textiles, and interdisciplinary design teams for pervasive computing. In 2006 he was selected for the National Science Foundation's Presidential Early Career Award for Scientists and Engineers (PECASE) for his research in e-textile-based wearable computing.

\section{Dr. Lisa D. McNair, Virginia Tech}

Lisa D. McNair is an Associate Professor of Engineering Education at Virginia Tech, where she also serves as co-Director of the VT Engineering Communication Center (VTECC) and CATALYST Fellow at the Institute for Creativity, Arts, and Technology (ICAT). Her research interests include interdisciplinary collaboration, design education, communication studies, identity theory and reflective practice. Projects supported by the National Science Foundation include exploring disciplines as cultures, interdisciplinary pedagogy for pervasive computing design; writing across the curriculum in Statics courses; as well as a CAREER award to explore the use of e-portfolios to promote professional identity and reflective practice.

\section{Dr. Marie C Paretti, Virginia Tech}

Marie C. Paretti is an Associate Professor of Engineering Education at Virginia Tech, where she codirects the Virginia Tech Engineering Communications Center (VTECC). Her research focuses on communication in engineering design, interdisciplinary communication and collaboration, design education, and gender in engineering. She was awarded a CAREER grant from the National Science Foundation to study expert teaching in capstone design courses, and is co-PI on numerous NSF grants exploring communication, design, and identity in engineering. Drawing on theories of situated learning and identity development, her work includes studies on the teaching and learning of communication, effective teaching practices in design education, the effects of differing design pedagogies on retention and motivation, the dynamics of cross-disciplinary collaboration in both academic and industry design environments, and gender and identity in engineering. 


\section{A Longitudinal Study of the Dimensions of Disciplinary Culture to Enhance Innovation and Retention among Engineering Students}

\section{Introduction}

Despite calls to promote creativity as "an indispensable quality for engineering" [1], the U.S. engineering educational system has been slow to develop pedagogies that successfully promote innovative behaviors. Although numerous sources recognize the growing scope and complexity of challenges that lie ahead in the 21 st century, engineering is struggling to balance its goals between the open-ended, vague, high-risk pursuit of innovation and the traditional "following the rules" and "only one possible good answer" problem-solving approach of producing functional, reliable applications. In short, engineers needs more creativity and interdisciplinary fluency, but not at the expense of its discipline-specific problem-solving skills. At the same time, engineering programs continue to struggle with attracting and retaining members of underrepresented populationswhose diversity could greatly contribute to innovation. Interestingly, this lack of diversity is often attributed to cultural traits of the field — often characterized as masculine, individualistic [2-7], and function-oriented. Notably, students in fields that emphasize functionality (e.g. engineering) rather than creativity (e.g. industrial design) express higher levels of uncertainty avoidance [8,9]. Together, these cultural dimensions of engineering continue to limit innovative practices, such as interdisciplinary collaboration, design thinking, and diversity of perspectives. The purpose of this study is to investigate patterns of cultural traits in students across disciplines, with the goal of building an actionable theory of engineering culture that can support pedagogies of inclusive and collaborative innovation.

Specifically, we propose to apply Hofstede's original four dimensions of national business cultures. The dimensions are power distance referring to the extent that individuals are comfortable (or not) in environments with unequal distribution of power [10]; uncertainty avoidance that addresses the level of comfort that individuals have with uncertainty [10]; individualism that refers to how the individual relate to the larger group [10]; and masculinity that addresses how assertive or caring individuals in a society are [10]. We are using the dimensions to adapt them to academic disciplines to explain how students develop skills to operate within and across disciplinary boundaries. Furthermore, we are exploring the relationships between these 
dimensions of disciplinary culture and student recruitment and retention, particularly for underrepresented groups. Specifically, this project is part of a NSF funded grant that is addressing the following six research questions:

RQ1: How do Hofstede's dimensions of national cultures map to academic disciplines?

RQ2: What are the relationships between the dimensions of culture and a) student choice of major, and b) student success with a major?

RQ3: How do students change over time in their academic programs with respect to the dimensions of culture?

RQ4: What factors affect those changes, e.g., pedagogical practices, curriculum, instructors?

RQ5: Do the relationships in RQ1-4 vary with demographic indicators, e.g., race or gender?

RQ6: What patterns of pedagogical practice operate within academic disciplines?

To address these issues, the grant is being developed in a 4-year study to investigate patterns of cultural traits in students across disciplines, and to build an actionable theory of engineering culture that can support pedagogies of inclusive and collaborative innovation as well as strategies for recruiting and retention efforts. In this paper, we present an update of the status of the grant and the preliminary results obtained so far.

\section{Literature Review}

Hofstede [11] introduced his conceptualization of culture after developing his theory of cultural dimensions in the mid-1960s. In his initial study, he analyzed the cultural differences among nations by surveying employees at IBM in more than 50 countries regarding their personal values. Hofstede's framework was first published in 1980 in his book "Cultural Consequences: The dimensions approach." Hofstede [12] initial definition of culture is developed based on his observations of the desired and desirable values of IBM's employees around the world. $\mathrm{He}$ described culture as a "collective programing of the mind." Individuals belonging to a specific culture have programmed their mind to act and behive according to what the software (culture) dictates. His definition of culture has evolved over time; in more recent books Hofstede, Hofstede, and M. Minkov [13] define culture as patterns of thinking, feeling, and acting that every human 
being carries. He has constructed a metaphor of culture as the software of the mind, based on his initial definition that culture is a collective programming od the mind, characterizing culture as a mental program that is developed by social interactions and experiences collected since the early life of an individual: "the programming starts within the family; it continues within the neighborhood, at school, in youth groups, at the workplace, and in the living community" (p. 6). More recently, Minkov and Hofstede [14] define culture as a "system of shared meanings that may be unique to a particular society or a group of societies" (p.4). Hofstede's original dimenisons of culture are [12]:

- Power Distance addresses the degree to the extent to which the "less powerful members of institutions and organizations within a country expect and accept that power is distributed unequally" (Hofstede et al., 2010; p.61). Notably, this dimension addresses inequity as defined and endorsed from below (i.e. the followers rather than the leaders) $[11,13]$. Exploring disciplines via this dimension can address patterns of student and faculty relationships, preferences for autonomy, communication patterns, and preferred problem types.

- Uncertainty Avoidance/Acceptance addresses the degree to which members of a culture can operate comfortably with uncertainty. According to Hofstede et al. [13] in cultures with high uncertainty avoidance, unstructured situations (novel, unknown, surprising, etc.) are perceived as intimidating; these cultures seek to minimize such situations via both legal controls (e.g. laws, rules, security measures), and religious philosophies that rest on absolute truth. Cultures that accept uncertainty, in contrast, tolerate diverse opinions, have fewer rules, and adopt more relativist philosophies. Exploring disciplines via this dimension can address students' abilities and willingness to collaborate, especially in interdisciplinary teams of unfamiliar territory, as well as their openness to creative formulations of problem solutions.

- Individualism/Collectivism addresses the relationship between individuals and the larger group. In an individualistic culture, individuals are loosely connected: everyone is expected to operate independently and people do not strongly identify with a group norm [13]. In collectivist cultures, people are tightly connected and consolidated into cohesive in-groups with strong emphasis on group norms and unity [13]. Exploring disciplines via 
this dimension can address participation of underrepresented populations in engineering, where collectivist interventions, such as living and learning communities, has proven to be effective social and academic support networks.

- Masculinity/Femininity refers to the continuum representing how emotional roles are distributed across genders, with assertive roles aligned with the masculine pole of the continuum and caring roles aligned with the feminine pole. Notably, in Hofstede's studies, women show less variation by culture than men; i.e. men are more assertive and competitive in masculine cultures, while women exhibit similar levels of caring in both masculine and feminine cultures. Masculine cultures thus experience a greater gap between men's and women's roles [13]. Exploring disciplines via this dimension may address women's participation in the masculinized culture of engineering that move beyond the metaphors of "pipeline" and "chilly climate."

Several authors have evaluated applications of Hofstede's dimensions in research, identifying problems such as (i) the use of nation as a unit to analyze culture [15-17]; (ii) the difficulties and limitations of a quantification of culture represented by cultural dimensions and matrices $[15,17-$ 19]; (iii) the ecological fallacy of assuming that dimensions developed at the national level also apply at the individual level $[15,20]$; and (iv) the use of data collected from a single company $[15,21]$ along with critiques of reliability [22-27] and validity [21, 23, 28-33] in Hofstede's instruments. Each of these critiques, while important, also has notable counterarguments.

First, as several authors have argued, countries should not be treated as unit of analysis. Any given nation may have multiple cultures present. Yet Hofstede based his theory on the assumption, from a sociology and anthropologist perspective, that differences in nations can be treated as similar to differences in cultures $[16,17,20]$. Second, in critiquing Hofstede's expression of culture as quantitatively measurable, researchers argue that because culture is dynamic and adaptive, it is a qualitative variable with meanings that depend upon context and external factors. Hofstede has countered by arguing that in defining cultural differences, quantitative data at the national level is all that is available, and such data is at least a useful starting point in understanding patterns on a large scale [10]. Third, in addressing the critique that Hofstede's instrument is flawed due to ecological fallacy, Brewer and Venaik [16] state that this 
false mapping may not exist if there is a theory of causation and that under specific situations, people may act according to the dimensions developed for the national level. They explain that despite the criticism of Hofstede's theory regarding ecological fallacy, the model is valuable to explain national-level phenomenon. Similarly, Grenness [20] affirms that "avoiding the ecological fallacy is possible when the aggregated data are collected from groups or samples which are assumed to be or known to be homogenous, e.g. sharing dominant cultural values" (p.80). Using the model thus requires an understanding of the population to be analyzed, including knowledge of the population's homogeneity or heterogeneity. Therefore, understanding how students understand their majors will minimize the ecological fallacy critique to Hofstede's model. Finally, Hofstede's framework and instrument have also received critiques of reliability and validity, including critiques regarding use of a single employer. However, since the original study was conducted, researchers have used Hofstede's instrument in different settings and confirmed internal consistency in its use $[34,35]$. Different studies have also addressed validity issues with positive results [34, 36]. Finally, several studies in the past three decades [37-49], even when not reporting instrument reliability or methodological validity, have successfully used Hofstede's theory to study cultural differences, arguing for the validity and reliability of the model overall.

Based on these studies, it is possible to argue that Hofstede's instrument and methodology can be reliable if confirmed by rigorous testing and, ensuring the necessary considerations of validity are met, can be a useful framework to study cultures and sub-cultures, such as academic disciplines. Our research will test the possibility of mapping cultural dimensions to academic disciplines, and particularly disciplines within engineering. We thus hypothesize that it will be possible to use Hofstede's theory to understand cultural differences in disciplines.

\section{Methods}

In order to answer our research questions, our research is a three-part study that examines the dimensions of culture across different universities using a mixed methods approach. The different phases of the project are as follows: 
- Phase 1 (Year 1): Survey of a stratified, university-wide sample (by discipline and academic year) of one institution students to address RQs 1, 2, and 5. In addition, sampling across academic years will provide a proxy for longitudinal data to develop a preliminary answer to RQ3 and inform subsequent data collection.

- Phase 2 (Years 2-4): We are surveying students at 6 different institutions, in Electrical and Computer Engineering (ECE), Industrial and Systems Engineering (ISE), and two departments outside engineering chosen based on the Year 1 results. This data will a) track individual students longitudinally (to answer RQ3), b) provide a detailed look at students' experiences within the major (to answer RQ4), and c) explore demographic patterns (to answer RQ5). In addition, annual qualitative interviews with a selected sample of participants will be used to more fully explain the quantitative results.

- Phase 3, Year 4: Collection of pedagogical practices to construct a local typology to be shared and vetted in workshops and focus groups with stakeholders, including faculty, industry representatives, and students. Feedback from stakeholders on culture findings compared with current practices will enable the research team to develop a theory of engineering culture that can inform pedagogies of innovation and collaboration.

We have chosen the departments of ECE and ISE within the college of engineering and partner sites for several reasons. First, both majors are innovative, large, and highly ranked relative to other departments nationwide. Second, both locally and nationally, these two departments are at opposite ends of the diversity spectrum, with ECE among the least diverse departments and ISE among the most diverse. Third, we hypothesize departmental differences along the individualism/collectivism dimension (ECE having a strongly individual culture, like many engineering majors, and ISE having a strong culture of team projects), providing at least some initial differential along Hofstede's model.

In this study, the first step was to use a quantitative approach to collect data from a version of Hofstede's survey developed by Sharma [50] in order to measure how students score regarding Hofstede's constructs. After a review of studies that used replicas and adaptations of Hofstede's 
instrument, and considering the various critiques, the research team selected the survey adapted by Sharma [50]. The survey was improved based on the analysis of the Cronbach's alpha of the pilot. In addition, to ensure validity, the survey was critiqued by the four authors of the project, who discussed every item in detail. In addition, an assessment expert evaluated the survey and made suggestions. Face validity and content validity were established with consensus of the researchers. The instrument, as mentioned before, has been proven to measure the theory developed by Hofstede. Our IRB-approved survey was delivered online using Qualtrics to a stratified sample of undergraduate students at research 6 different partner institutions. Table 1 presents information about the sample size, and majors by semester obtained in each institution in the first 3 years.

Table 1. Sample sizes by institution

\begin{tabular}{|c|c|c|c|c|c|c|}
\hline & \multicolumn{2}{|c|}{ Spring 2014} & \multicolumn{2}{|c|}{ Fall 2014} & \multicolumn{2}{|c|}{ Spring 2015} \\
\hline & Sample size & Major/sem & Sample size & Major/sem. & Sample size & Major/sem. \\
\hline Institution 1 & & & 96 & $\begin{array}{l}\text { CS, CE, EE, IE } \\
\text { All semesters }\end{array}$ & 35 & $\begin{array}{c}\text { CS, CE, EE, IE } \\
\text { Sophomore }\end{array}$ \\
\hline Institution 2 & & & 32 & $\begin{array}{c}\text { ECE, ISE } \\
\text { All semesters }\end{array}$ & 28 & $\begin{array}{c}\text { ECE, ISE } \\
\text { Sophomore }\end{array}$ \\
\hline Institution 3 & 877 & $\begin{array}{l}\text { All majors } \\
\text { semesters }\end{array}$ & 471 & $\begin{array}{l}12 \text { majors } \\
\text { All semesters }\end{array}$ & 36 & $\begin{array}{c}\text { CS, ECE, ISE } \\
\text { Sophomore }\end{array}$ \\
\hline Institution 4 & & & 45 & $\begin{array}{c}\text { ECE, ISE } \\
\text { All semesters }\end{array}$ & & \\
\hline Institution 5 & & & 60 & $\begin{array}{c}\text { CE, CS, EE } \\
\text { All semesters }\end{array}$ & 10 & $\begin{array}{l}\text { CE, CS, EE } \\
\text { Sophomore }\end{array}$ \\
\hline Institution 6 & & & & & 24 & $\begin{array}{l}\text { CS, IE, SE } \\
\text { Sophomore }\end{array}$ \\
\hline Institution 7 & & & & & 8 & $\begin{array}{c}\text { IE, SE } \\
\text { Sophomore }\end{array}$ \\
\hline
\end{tabular}


Data were processed using SPSS software; descriptive and inferential statistics were analyzed. Responses were grouped by discipline and the four dimensions proposed by Hofstede were measured. Results recorded the arithmetic means for each major based on a 7-point Likert scale:

- For Individualism/Collectivism, 1 is considered to be less individualistic (more collectivistic) and 7 is considered highly individualistic.

- For Power Distance, 7 is considered to have a high power distance (more comfort with/support of hierarchies)

- For Uncertainty Avoidance, 7 is considered higher resistance to uncertainty.

- For Masculinity/Femininity, 1 is the lower value for Masculinity, representing a disposition toward femininity (caring), while 7 is the higher value of Masculinity (assertivenes).

In addition to the qualitative analyisis, a qualitative approach will allow us was developed in order to understand more deeply students' experiences regarding their major in terms of individualism, power distance, uncertainty avoidance, and masculinity. A semi-structured interview is being conducted in order to understand how engineering students define their disciplinary engineering culture using Hofstede's dimensions as the guide.

An initial interview protocol was developed based on the answers that students provided in the quantitative study, the information collected on the systematic review of the literature, and also informed by theory proposed by Bradbeer [51] and Nulty and Barrett [52]. The initial protocol was piloted with 2 graduate students. Revisions were made and a pilot study was conducted were 5 undergraduate electrical and computer engineering students were interviewed for one hour. The preliminary results were analyzed using the qualitative data analysis software MaxQDA and 4 graduate students coded the interview transcripts. Over several meetings the codes were discussed and the 4 researchers agreed on the improvements needed on the protocol. The protocol was updated and was reviewed by 4 graduate students and 3 faculty members. The current protocol is approved by IRB. Twelve students will be the participants on the study. 6 will be from Industrial engineering, and 6 from Electrical and computer engineering. The reasons behind selecting these majors were explained previously. Interviews will last less than one hour and will be audio 
recorded. Recordings will be transcribed by the resarchers to get familiar with the data. Students will sign a consent form and pseudonyms will be used when transcribing the audio recording to ensure confidentiality. Data will be analyzed using the qualitative data management software MaxQDA that allows to visually incorporate codes and memos to the transcripts of the interviews.

\section{Results and Discussion}

Results from the survey are presented in tables 2 to 7 . Means of the scores for each discipline are reported for each major. Also, the standard deviation and sample size is presented. After analyzing the descriptive statistics, we conducted some inferential statistics using T-tests to determine if the differences regarding how disciplines score on a specific dimension of culture were significant.

Table 2. Arithmetic mean and standard deviation of responses for cultural dimensions in institution \#1

\begin{tabular}{|l|c|c|c|c|c|c|c|c|}
\hline \multirow{2}{*}{ Major / semester } & \multicolumn{7}{|c|}{ Cultural Dimensions } \\
\cline { 2 - 9 } & \multicolumn{2}{|c|}{ Individualism } & \multicolumn{2}{c|}{ Power Distance } & \multicolumn{2}{c|}{ Uncertainty Avoidance } & \multicolumn{2}{c|}{ Masculinity } \\
\cline { 2 - 9 } & Mean & Std. Dev & Mean & Std. Dev & Mean & Std. Dev & Mean & Std. Dev \\
\hline $\begin{array}{l}\text { Industrial Eng. } \\
\text { (n=9) Fall'14 }\end{array}$ & 3.944 & 2.149 & 3.431 & 1.777 & 3.847 & 1.589 & 5.133 & 1.847 \\
\hline $\begin{array}{l}\text { Electrical Eng. } \\
(\mathrm{n}=29) \text { Fall'14 }\end{array}$ & 4.004 & 2.046 & 3.397 & 1.863 & 4.379 & 1.788 & 5.319 & 1.709 \\
\hline $\begin{array}{l}\text { Comp Sc. } \\
\text { Software Eng. } \\
\text { (n=34) Fall'14 }\end{array}$ & 4.099 & 2.013 & 3.371 & 1.602 & 4.397 & 1.509 & 5.202 & 1.769 \\
\hline $\begin{array}{l}\text { Computer Eng. } \\
\text { (n=24) Fall'14 }\end{array}$ & 3.984 & 2.038 & 3.589 & 1.791 & 4.318 & 1.598 & 4.938 & 1.729 \\
\hline $\begin{array}{l}\text { Industrial Eng. } \\
\text { (n=9) Spring'15 }\end{array}$ & 3.417 & 1.798 & 3.389 & 1.724 & 4.083 & 1.518 & 5.222 & 1.886 \\
\hline $\begin{array}{l}\text { Comp Sc. } \\
\text { Software Eng. } \\
\text { (n=34) Spring'15 }\end{array}$ & 3.758 & 1.910 & 3.008 & 1.565 & 4.438 & 1.630 & 5.070 & 2.067 \\
\hline $\begin{array}{l}\text { Computer Eng. } \\
\text { (n=7) Spring'15 }\end{array}$ & 3.607 & 2.278 & 3.125 & 1.466 & 4.125 & 1.562 & 4.893 & 1.670 \\
\hline
\end{tabular}

Note: Every dimension was measured on a Likert scale from 1 to 7. 
Table 3. Arithmetic mean and standard deviation of responses for cultural dimensions in institution \# 2

\begin{tabular}{|l|c|c|c|c|c|c|c|c|}
\hline \multirow{2}{*}{ Major / semester } & \multicolumn{7}{|c|}{ Cultural Dimensions } \\
\cline { 2 - 9 } & \multicolumn{2}{|c|}{ Individualism } & \multicolumn{1}{c|}{ Power Distance } & \multicolumn{2}{c|}{ Uncertainty Avoidance } & \multicolumn{2}{c|}{ Masculinity } \\
\cline { 2 - 9 } & Mean & Std. Dev & Mean & Std. Dev & Mean & Std. Dev & Mean & Std. Dev \\
\hline $\begin{array}{l}\text { E.C.E. } \\
\text { (n=27) Fall'14 }\end{array}$ & 3.838 & 2.224 & 3.579 & 1.939 & 4.250 & 1.843 & 5.343 & 1.803 \\
\hline $\begin{array}{l}\text { I.S.E. } \\
(\mathrm{n}=5 \text { ) Fall'14 }\end{array}$ & 3.175 & 2.427 & 2.850 & 2.032 & 4.250 & 1.958 & 5.025 & 2.118 \\
\hline $\begin{array}{l}\text { E.C.E. } \\
(\mathrm{n}=) \text { Spring'15 }\end{array}$ & 3.611 & 1.926 & 3.792 & 1.527 & 3.625 & 1.646 & 4.667 & 1.807 \\
\hline $\begin{array}{l}\text { I.S.E. } \\
\text { (n=) Spring'15 }\end{array}$ & 3.500 & 2.588 & 3.375 & 1.952 & 3.208 & 1.744 & 5.333 & 1.606 \\
\hline
\end{tabular}

Note: Every dimension was measured on a Likert scale from 1 to 7.

Table 4. Arithmetic mean and standard deviation of responses for cultural dimensions in Institution \# 3

\begin{tabular}{|c|c|c|c|c|c|c|c|c|}
\hline \multirow{3}{*}{ Major } & \multicolumn{8}{|c|}{ Cultural Dimensions } \\
\hline & \multicolumn{2}{|c|}{ Individualism } & \multicolumn{2}{|c|}{ Power Distance } & \multicolumn{2}{|c|}{ Uncertainty Avoidance } & \multicolumn{2}{|c|}{ Masculinity } \\
\hline & Mean & Std. Dev & Mean & Std. Dev & Mean & Std. Dev & Mean & Std. Dev \\
\hline $\begin{array}{l}\text { Architecture } \\
(\mathrm{n}=58)\end{array}$ & 5.879 & 0.640 & 3.289 & 0.800 & 3.966 & 1.058 & 5.060 & 0.585 \\
\hline $\begin{array}{l}\text { Chemistry } \\
(\mathrm{n}=26)\end{array}$ & 6.042 & 0.144 & 3.083 & 0.711 & 6.042 & 0.144 & 4.833 & 0.564 \\
\hline $\begin{array}{l}\text { Communication } \\
(\mathrm{n}=10)\end{array}$ & 6.063 & 0.554 & 3.650 & 0.984 & 4.038 & 1.138 & 5.288 & 0.334 \\
\hline $\begin{array}{l}\text { Comp Engineering } \\
(\mathrm{n}=38)\end{array}$ & 5.605 & 0.846 & 3.211 & 1.034 & 4.431 & 1.223 & 5.099 & 0.866 \\
\hline $\begin{array}{l}\text { Electrical Eng. } \\
(\mathrm{n}=43)\end{array}$ & 5.534 & 0.817 & 3.471 & 0.843 & 4.331 & 1.073 & 5.299 & 0.597 \\
\hline $\begin{array}{l}\text { English } \\
(\mathrm{n}=31)\end{array}$ & 5.698 & 0.589 & 3.238 & 0.884 & 4.573 & 0.992 & 5.048 & 0.597 \\
\hline $\begin{array}{l}\text { History } \\
(\mathrm{n}=22)\end{array}$ & 5.847 & 0.628 & 3.159 & 0.847 & 4.136 & 0.874 & 5.142 & 0.622 \\
\hline $\begin{array}{l}\text { Industrial Design } \\
(\mathrm{n}=18)\end{array}$ & 5.931 & 0.400 & 2.861 & 0.845 & 3.389 & 0.944 & 4.924 & 0.491 \\
\hline $\begin{array}{l}\text { Industrial and } \\
\text { Systems Eng. } \\
(\mathrm{n}=34)\end{array}$ & 6.018 & 0.537 & 3.316 & 0.888 & 4.018 & 1.057 & 5.206 & 0.482 \\
\hline $\begin{array}{l}\text { Marketing } \\
(\mathrm{n}=17)\end{array}$ & 5.963 & 0.402 & 3.353 & 0.735 & 3.949 & 1.263 & 5.529 & 0.495 \\
\hline $\begin{array}{l}\text { Mathematics } \\
(\mathrm{n}=40)\end{array}$ & 5.572 & 0.732 & 3.672 & 1.013 & 4.903 & 0.935 & 5.216 & 0.544 \\
\hline $\begin{array}{l}\text { Physics } \\
(\mathrm{n}=39)\end{array}$ & 5.926 & 0.764 & 3.067 & 0.903 & 4.179 & 1.056 & 5.032 & 0.641 \\
\hline $\begin{array}{l}\text { Political Science } \\
(\mathrm{n}=2)\end{array}$ & 5.938 & 0.619 & 3.688 & 0.088 & 4.063 & 1.503 & 5.438 & 0.265 \\
\hline $\begin{array}{l}\text { Sociology } \\
(\mathrm{n}=20)\end{array}$ & 5.881 & 0.542 & 3.475 & 0.993 & 4.588 & 1.078 & 5.256 & 0.424 \\
\hline
\end{tabular}

Note: Every dimension was measured on a Likert scale from 1 to 7. 
Table 5. Arithmetic mean and standard deviation of responses for cultural dimensions in institution \#4

\begin{tabular}{|l|c|c|c|c|c|c|c|c|}
\hline \multirow{2}{*}{ Major / semester } & \multicolumn{9}{|c|}{ Cultural Dimensions } \\
\cline { 2 - 9 } & \multicolumn{2}{|c|}{ Individualism } & \multicolumn{2}{c|}{ Power Distance } & \multicolumn{2}{c|}{ Uncertainty Avoidance } & \multicolumn{2}{c|}{ Masculinity } \\
\cline { 2 - 8 } & Mean & Std. Dev & Mean & Std. Dev & Mean & Std. Dev & Mean & Std. Dev \\
\hline $\begin{array}{l}\text { E.C.E. } \\
\text { (n=44) Fall'14 }\end{array}$ & 3.935 & 2.042 & 3.565 & 1.675 & 4.494 & 1.578 & 5.361 & 1.577 \\
\hline $\begin{array}{l}\text { Industrial Eng. } \\
(\mathrm{n}=1) \text { Fall'14 }\end{array}$ & 3.500 & & 3.000 & & 4.875 & & 5.875 & \\
\hline
\end{tabular}

Note: Every dimension was measured on a Likert scale from 1 to 7.

Table 6. Arithmetic mean and standard deviation of responses for cultural dimensions in institution \# 5

\begin{tabular}{|l|c|c|c|c|c|c|c|c|}
\hline \multirow{2}{*}{ Major / semester } & \multicolumn{7}{|c|}{ Cultural Dimensions } \\
\cline { 2 - 9 } & \multicolumn{2}{|c|}{ Individualism } & \multicolumn{1}{c|}{ Power Distance } & Uncertainty Avoidance & \multicolumn{2}{c|}{ Masculinity } \\
\cline { 2 - 9 } & Mean & Std. Dev & Mean & Std. Dev & Mean & Std. Dev & Mean & Std. Dev \\
\hline $\begin{array}{l}\text { Electrical Eng. } \\
\text { (n=20) Fall'14 }\end{array}$ & 3.729 & 2.201 & 4.146 & 1.766 & 4.368 & 1.676 & 5.493 & 1.656 \\
\hline $\begin{array}{l}\text { Computer science } \\
\text { (n=20) Fall'14 }\end{array}$ & 4.063 & 2.203 & 4.125 & 1.939 & 4.931 & 1.720 & 5.350 & 1.514 \\
\hline $\begin{array}{l}\text { Computer Eng. } \\
\text { (n=18) Fall'14 }\end{array}$ & 3.847 & 1.991 & 3.472 & 1.630 & 4.389 & 1.622 & 5.282 & 1.735 \\
\hline $\begin{array}{l}\text { Electrical Eng. } \\
\text { (n=6) Spring'15 }\end{array}$ & 3.604 & 1.865 & 3.208 & 1.675 & 4.667 & 1.326 & 5.188 & 1.818 \\
\hline $\begin{array}{l}\text { Computer science } \\
\text { (n=3) Spring'15 }\end{array}$ & 4.417 & 2.225 & 4.000 & 1.888 & 4.583 & 1.692 & 5.292 & 2.074 \\
\hline $\begin{array}{l}\text { Computer Eng. } \\
\text { (n=1) Spring'15 }\end{array}$ & 3.625 & & 2.500 & & 4.500 & & 5.375 & \\
\hline
\end{tabular}

Note: Every dimension was measured on a Likert scale from 1 to 7.

Table 7. Arithmetic mean and standard deviation of responses for cultural dimensions in institution \#6

\begin{tabular}{|l|c|c|c|c|c|c|c|c|}
\hline \multirow{2}{*}{ Major / semester } & \multicolumn{7}{|c|}{ Cultural Dimensions } \\
\cline { 2 - 9 } & \multicolumn{2}{|c|}{ Individualism } & \multicolumn{2}{c|}{ Power Distance } & Uncertainty Avoidance & \multicolumn{2}{c|}{ Masculinity } \\
\cline { 2 - 9 } & Mean & Std. Dev & Mean & Std. Dev & Mean & Std. Dev & Mean & Std. Dev \\
\hline $\begin{array}{l}\text { Industrial Eng. } \\
\text { (n=16) Spring'15 }\end{array}$ & 3.844 & 2.086 & 3.250 & 1.684 & 4.424 & 1.856 & 5.305 & 1.585 \\
\hline $\begin{array}{l}\text { Computer Science } \\
\text { (n= 5) Spring'15 }\end{array}$ & 4.400 & 1.959 & 3.475 & 1.694 & 4.919 & 1.411 & 5.350 & 1.511 \\
\hline $\begin{array}{l}\text { Software Eng. } \\
\text { (n=3) Spring'15 }\end{array}$ & 3.042 & 2.010 & 3.458 & 2.043 & 3.310 & 1.574 & 5.333 & 1.761 \\
\hline
\end{tabular}

Note: Every dimension was measured on a Likert scale from 1 to 7. 
After conducting several inferential statistics tests (T-tests, Anova), there are no apparently differences between the responses by major or by institution. Overall, students in every major tend to have a medium-high individualistic score (i.e. to be more independent). That means that students perceive their independence working on school-related tasks important. We argued that disciplines like electrical and computer engineering, and mathematics required more individualistic work. Instead, disciplines like industrial engineering, marketing, industrial design, and sociology rely more on collective work like team projects.

Overall, students tend to have medium-low scores for power distance. They are not confortable being dominated by people with authority coming from positions of high power, neither feel intimidated about it. We could not find statistical significant differences in power distance scores. One thing to consider is the emphasis made in higher education recently to promote students' awareness of their rights and the importance of fairness and justice that can influence how students perceive this dimension. Also, they tend to avoid uncertainty having high scores on this dimension. Students prefer to have clear instructions and not take many risks. Although masculinity was probably the dimension with more diverse responses between different majors, in general students tend to be more assertive (masculinity) than caring (femininity). This results compare with Hofstede [13] results for the United States as a country regarding each dimension. Therefore, we can conclude that the instrument is measuring the national culture rather than the disciplinary culture. Despite the fact that we didn't find any statistically significant differences using the survey, Hofstede's dimensions are valuable to help us develop the interview protocol and use the dimensions as a reference to obtain more in depth information on how undergraduate students understand their disciplinary culture.

\section{Limitations}

One limitation of the study is generalization of the findings. The data may not be representative of the majors studied. Neither can we make inferences of the engineering student population as a whole. To address this concern, we are actively working to minimize threats to internal and external validity by including partner institutions in the data collection. In addition, the next phase 
of the study consisted of qualitative data collection that will allow us to obtain more rich information regarding how students understand their disciplinary culture.

\section{Intellectual merit}

The primary goals of this research are 1) to determine if and how Hofstede's national cultures map to disciplinary cultures in universities, and 2) to formulate an actionable theory for promoting innovation curricula and strategies for recruiting and retention efforts. While Hofstede's theory is correlational rather than causal, we argue that a better understanding of disciplinary culture from the perspective of characteristics aligned with innovation will help identify needed interventions and shape pedagogical practices that effectively enhance innovation skills for engineering students. The mixed methods research is organized cohesively to address research questions that explore the role of disciplinary culture in engineering education. Participation by engineering departments at partner universities will yield results grounded in a variety of institutional contexts.

Consequently, the intellectual merit of this proposal lies in its ability to develop a theory to describe relationships between disciplinary culture and the outcomes of engineering education; this theory can then inform targeted curricular interventions to enhance the innovative and collaborative abilities of engineering students. This theory would have explanatory power for a range of characteristics of engineering students and programs, from the difficulties students face when dealing with unstructured, open-ended design problems, to the inability of certain fields (e.g., computer engineering) to recruit and retain students from underrepresented groups.

The longitudinal nature of the proposed research will also provide insights regarding the degree to which program outcomes are linked to incoming student characteristics versus features of the program itself (Astin \& Oseguera, 2002). Although not a controlled experiment, the longitudinal tracking of individual students can yield insights into programmatic effects by exploring how different incoming student populations develop in response to types of curricular experiences. A theory linking dimensions of culture to pedagogical practices can thus help predict potential 
benefits of particular curricular changes. More importantly, the theory can guide the development and implementation of beneficial changes.

\section{Acknowledment}

This material is based upon work supported by the National Science Foundation under Grant No. EEC-1329224. Any opinions, findings, and conclusions or recommendations expressed in this material are those of the author(s) and do not necessarily reflect the views of the National Science Foundation.

\section{References}

1. Clough, G.W., The engineer of 2020: Visions of engineering in the new century. National Academy of Engineering, Washington, DC, 2004.

2. Dryburgh, H., WORK HARD, PLAY HARD Women and Professionalization in Engineering-Adapting to the Culture. Gender \& Society, 1999. 13(5): p. 664-682.

3. Faulkner, W., Dualisms, hierarchies and gender in engineering. Social Studies of Science, 2000. 30(5): p. 759-792.

4. Faulkner, W., Nuts and Bolts and People'Gender-Troubled Engineering Identities. Social studies of science, 2007. 37(3): p. 331-356.

5. Henwood, F., Engineering difference: discourses on gender, sexuality and work in a college of technology. Gender and education, 1998. 10(1): p. 35-49.

6. Tonso, K.L., On the outskirts of engineering: Learning identity, gender, and power via engineering practice. 2007: Sense Publishers.

7. Tonso, K.L., Teams that work: Campus culture, engineer identity, and social interactions. Journal of Engineering Education, 2006. 95(1): p. 25-37.

8. Kim, K. and L.D. McNair. The Impact of Disciplinary Balance on Interdisciplinary Teamwork A Comparative Case Study of Interdisciplinary Product Design Teams. in Proceedings of the Human Factors and Ergonomics Society Annual Meeting. 2011. SAGE Publications.

9. Kim, K., et al. Situativity approaches for improving interdisciplinary team processes. in American Society for Engineering Education Southeast Section Conference. Blacksburg. 2010.

10. Hofstede, G., Dimensions do not exist: A reply to Brendan McSweeney. Human relations, 2002. 55(11): p. 1355-1361.

11. Hofstede, G., Culture and Organizations. Intercultural Cooperation and its Importance for Survival, Software of the Mind. 1993, McGraw-Hill: Great Britain.

12. Hofstede, G., Culture's consequences: The dimensions approach. Vol. 5. 1980: sage.

13. Hofstede, G., G. Hofstede, and M. Minkov, Cultures and organizations - Software of the Mind. 2nd ed. 2010: McGraw-Hill New York.

14. Minkov, M. and G. Hofstede, Cultural differences in a globalizing world. 2013: Emerald Group Publishing.

15. Baskerville, R.F., Hofstede never studied culture. Accounting, organizations and society, 2003. 28(1): p. 1-14. 
16. Brewer, P. and S. Venaik, On the misuse of national culture dimensions. International Marketing Review, 2012. 29(6): p. 673-683.

17. McSweeney, B., Hofstede's model of national cultural differences and their consequences: A triumph of faitha failure of analysis. Human relations, 2002. 55(1): p. 89-118.

18. Hampden-Turner, C. and F. Trompenaars, Response to Geert Hofstede. International Journal of Intercultural Relations, 1997. 21(1): p. 149-159.

19. Ford, D.P., C.E. Connelly, and D.B. Meister, Information systems research and Hofstede's culture's consequences: an uneasy and incomplete partnership. Engineering Management, IEEE Transactions on, 2003. 50(1): p. 8-25.

20. Grenness, T., Hofstede Revisited: Is Making the Ecological Fallacy when Using Hofstede's Instrument on Individual Behavior Really Unavoidable? International Journal of Business \& Management, 2012. 7(7).

21. Søndergaard, M., Research note: Hofstede's consequences: a study of reviews, citations and replications. Organization studies, 1994. 15(3): p. 447-456.

22. Javidan, M., et al., Conceptualizing and measuring cultures and their consequences: a comparative review of GLOBE's and Hofstede's approaches. Journal of international business studies, 2006. 37(6): p. 897-914.

23. Blodgett, J., A. Bakir, and G. Rose, A test of the validity of Hofstede's cultural framework. Journal of Consumer Marketing, 2008. 25(6): p. 339-349.

24. Spector, P.E., C.L. Cooper, and K. Sparks, An international study of the psychometric properties of the Hofstede Values Survey Module 1994: A comparison of individual and country/province level results. Applied Psychology, 2001. 50(2): p. 269-281.

25. Fischer, R., et al., Are individual-level and country-level value structures different? Testing Hofstede's legacy with the Schwartz Value Survey. Journal of Cross-Cultural Psychology, 2010. 41(2): p. 135-151.

26. Merritt, A., Culture in the Cockpit Do Hofstede's Dimensions Replicate? Journal of cross-cultural psychology, 2000. 31(3): p. 283-301.

27. Chanchani, S. and P. Theivanathampillai, Typologies of culture. University of Otago, Department of Accountancy and Business Law Working Papers Series, 2002. 4(10): p. 02.

28. Wallace, J., J. Hunt, and C. Richards, The relationship between organisational culture, organisational climate and managerial values. International Journal of Public Sector Management, 1999. 12(7): p. 548-564.

29. Lowie, R.H., Culture \& ethnology. 1917: DC McMurtrie.

30. Soares, A.M., M. Farhangmehr, and A. Shoham, Hofstede's dimensions of culture in international marketing studies. Journal of business research, 2007. 60(3): p. 277-284.

31. Chiang, F., A critical examination of Hofstede's thesis and its application to international reward management. The International Journal of Human Resource Management, 2005. 16(9): p. 1545-1563.

32. Fernandez, D.R., et al., Hofstede's country classification 25 years later. The Journal of social psychology, 1997. 137(1): p. 43-54.

33. Reisinger, Y. and J.C. Crotts, Applying Hofstede's national culture measures in tourism research: Illuminating issues of divergence and convergence. Journal of Travel Research, 2010. 49(2): p. 153-164.

34. Ang, S., L. Van Dyne, and T.M. Begley, The employment relationships of foreign workers versus local employees: A field study of organizational justice, job satisfaction, performance, and OCB. Journal of Organizational Behavior, 2003. 24(5): p. 561-583.

35. Ardichvili, A. and K.P. Kuchinke, Leadership styles and cultural values among managers and subordinates: a comparative study of four countries of the former Soviet Union, Germany, and the US. Human Resource Development International, 2002. 5(1): p. 99-117.

36. Marcus, A. User-interface design, culture, and the future. in Proceedings of the Working Conference on Advanced Visual Interfaces. 2002. ACM.

37. At-Twaijri, M.I. and I.A. Al-Muhaiza, Hofstede's cultural dimensions in the GCC countries: An empirical investigation. International Journal of Value-Based Management, 1996. 9(2): p. 121-131.

38. Cheung, H.Y. and A.W.H. Chan, Education and competitive economy: how do cultural dimensions fit in? Higher Education, 2010. 59(5): p. 525-541.

39. Elenkov, D.S. and I.M. Manev, Top management leadership and influence on innovation: The role of sociocultural context. Journal of management, 2005. 31(3): p. 381-402.

40. Entrekin, L. and Y.W. Chung, Attitudes towards different sources of executive appraisal: a comparison of Hong Kong Chinese and American managers in Hong Kong. International Journal of Human Resource Management, 2001. 12(6): p. 965-987. 
41. Giacobbe-Miller, J.K., et al., Country and organizational-level adaptation to foreign workplace ideologies: A comparative study of distributive justice values in China, Russia and the United States. Journal of International Business Studies, 2003. 34(4): p. 389-406.

42. Heuer, M., J.L. Cummings, and W. Hutabarat, Cultural stability or change among managers in Indonesia? Journal of International Business Studies, 1999: p. 599-610.

43. Li, C., et al., Ethnicity as a variable in leisure research. Journal of Leisure Research, 2007. 39(3): p. 514.

44. Liu, L., et al. Understanding chinese characteristics of requirements engineering. in Requirements Engineering Conference, 2009. RE'09. 17th IEEE International. 2009. IEEE.

45. Naumov, A. and S. Puffer, Measuring Russian culture using Hofstede's dimensions. Applied psychology, 2000. 49(4): p. 709-718.

46. Prašnikar, J., M. Pahor, and J. Vidmar Svetlik, Are national cultures still important in international business? Russia, Serbia and Slovenia in comparison. Management: Journal of Contemporary Management Issues, 2008. 13(2 (Special issue)): p. 1-26.

47. Tang, L. and P.E. Koveos, A framework to update Hofstede's cultural value indices: economic dynamics and institutional stability. Journal of International Business Studies, 2008. 39(6): p. 1045-1063.

48. Twati, J.M., The influence of societal culture on the adoption of information systems: The case of Libya. Communications of the IIMA, 2008. 8(1): p. 1-12.

49. Yoon, C., The effects of national culture values on consumer acceptance of e-commerce: Online shoppers in China. Information \& Management, 2009. 46(5): p. 294-301.

50. Sharma, P., Measuring personal cultural orientations: scale development and validation. Journal of the Academy of Marketing Science, 2010. 38(6): p. 787-806.

51. Bradbeer, J., Barriers to interdisciplinarity: Disciplinary discourses and student learning. Journal of Geography in Higher Education, 1999. 23(3): p. 381-396.

52. Nulty, D.D. and M.A. Barrett, Transitions in students' learning styles. Studies in higher education, 1996. 21(3): p. 333-345. 